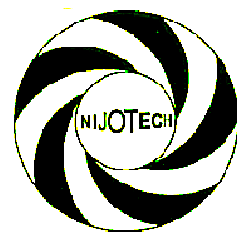

Nigerian Journal of Technology (NIJOTECH) Vol. 33. No. 1.January 2014, pp $\mathbf{4 3}-\mathbf{4 8}$

Copyright@ Faculty of Engineering,

University of Nigeria, Nsukka, ISSN: $1115-8443$

www.nijotech.com

http://dx.doi.org/10.4314/njt.v33i1.6

\title{
EFFECTS OF SULPHUR ADDITION ON MICROSTRUCTURAL MODIFICATION AND MECHANICAL PROPERTIES OF SAND CAST Al-12wt\% Si ALLOY
}

\author{
C. W. Onyia' ${ }^{1}$, B. A. Okorie ${ }^{2,}{ }^{*}$, N. I. Amalu ${ }^{3}$ and S. I. Neife ${ }^{4}$ \\ 1Dept. of Metallurgical and Materials Eng'G, Enugu State Univ. of Science and Technology, Enugu, Nigeria \\ 2,4 Dept. of Metallurgical and Materials Engineering, University of Nigeria, NsukKa, Nigeria \\ 3PRojects DEVElopment InSTITUTE, ENUGU, NigERIA
}

E-mail addresses: ${ }^{1}$ chikezieonyia@yahoo.com, ${ }^{2}$ bonokorie@yahoo.com, ${ }^{3}$ ninablaise5050@yahoo.com 4 drneifes@gmail.com,

\section{Abstract}

The effects of sulphur addition on the microstructure and mechanical properties of sand cast Al-12wt\%Si alloy have been investigated in this study. For this purpose, different amounts of sulphur were added to Al-12wt\%Si alloy in an induction furnace to produce sand castings for micro-structural and mechanical properties analyses. Tensile and hardness tests were carried out to determine the mechanical properties while optical microscopy was used to investigate the microstructure of the cast samples. The results showed that the addition of sulphur to Al-12wt\%Si alloy modified the Al-Si eutectic morphology from needle-like (flake-like) eutectic silicon structure to fine-globule eutectic silicon structure. The optimum modification level of sulphur was found to be $0.02-0.05 \%$ of the weight of the alloy. Increase in concentration of sulphur above the optimum level of modification decreased the degree of fineness of the eutectic silicon structure with significant decrease in mechanical properties of the alloy and this is suggested to be a result of the formation of brittle sulphur compound at the grain boundaries of the alloy when the optimum concentration was exceeded.

Keywords: Aluminum alloys; sand casting; microstructure; mechanical properties; optical microscopy

\section{Introduction}

The Al-12wt\%Si alloy is an important Al-Si57 casting alloy. This alloy represents a typical58 composition for a cast alloy because it has the59 lowest possible melting temperature $\left(577^{\circ} \mathrm{C}\right) 60$ which is its eutectic temperature [1]. Al-Si61 eutectic is an irregular and coupled eutectic, and71 the eutectic silicon is believed to be the leading72 phase in unmodified alloys, growing ahead of the 73 eutectic aluminum during solidification [2]. The Al-Si eutectic undergoes a change in75 morphology upon addition of trace amount of76 certain elements e.g. strontium and sodium, and77 this process is often referred to as eutectic78 modification. Modification transforms the brittle,79 coarse and acicular eutectic silicon in the80 unmodified structure to fine fibrous eutectic81 silicon in the modified structure with attendant 82 improvement in mechanical properties of the83 alloy [3-6]. As a result of its commercial84 importance, study of this phenomenon of85
56 modification has been the subject of intense research efforts dating back to early 1920s till today. Pacz [7] discovered that Al-Si alloys containing between 5 and $15 \%$ Si could be treated with fluxes of alkali fluorides to yield alloys of improved ductility and machinability.

Over the years, many research works on modification have been carried out and a number of conflicting theories have been advanced to explain modification. In most of the experimental studies on modification, there is a general suggestion that modification involves the neutralization or poisoning of potent eutectic silicon nucleants; AIP $[8,9]$ and $\beta-(\mathrm{Al}, \mathrm{Si}$, $\mathrm{Fe})$ [10], during eutectic nucleation resulting in supercooling of the melt, and restriction of the eutectic silicon growth during eutectic growth which also results in supercooling of the melt. Eutectic silicon, at this large supercooling, nucleates and grows isotropically into fine fibrous structure through the channels between 
1 the eutectic aluminum cells that have been44

2 made to nucleate and grow ahead of the silicon 45

3 at higher temperature. 46

4 The most common modifiers used in the 47

5 industry are sodium and strontium [11]. The48

6 limitations of the use of strontium as a modifier49

7 are its high cost and the increased porosity level50

8 in castings modified with strontium [12-16]51

9 The limitation of the use of sodium is that52

10 sodium is easily lost from the melt by53

11 volatilization [16].

12 There is then need for further research work on55

13 the modification of Al-Si cast alloys. Research56

14 has scarcely been done on modification of57

15 eutectic Al-Si cast alloys with sulphur. In this58

16 study attempts were made to modify Al-59

$1712 \mathrm{wt} \%$ Si sand cast alloy with sulphur.

18

192

\section{Experimental Procedure}

\subsection{Production of Al-12wt\%Si Alloy}

In the present investigation, the charge64 materials consisted of commercial purity65 aluminum and silicon. Table 1 shows their66 individual chemical compositions.67 Degasification of the melt was done with $\mathrm{MnCl}_{2} .68$ Sulphur, in elemental form, was used to modify 69 the alloy.

Table 1: Chemical composition of the charge 71

\begin{tabular}{cccc} 
& materials & & 72 \\
\hline Element & Aluminum & Silicon & 73 \\
$\mathrm{Al}$ & 99.71 & 0.185 & 74 \\
$\mathrm{Si}$ & 0.045 & 99.341 & 75 \\
$\mathrm{Ca}$ & - & 0.082 & 76 \\
$\mathrm{Fe}$ & 0.230 & 0.392 & 77 \\
$\mathrm{Cu}$ & 0.002 & - & 78 \\
$\mathrm{Zn}$ & 0.006 & - & 79 \\
$\mathrm{Mn}$ & 0.001 & - & 80 \\
$\mathrm{Mg}$ & 0.001 & - & 81 \\
$\mathrm{Cr}$ & 0.001 & - & 82 \\
$\mathrm{~B}$ & 0.004 & - &
\end{tabular}

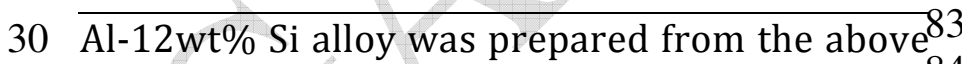
31 charge materials in a clay graphite crucible in an 84 32 induction furnace and the melt was held at 85 $33750^{\circ} \mathrm{C}$. After degassing with manganese chloride 86 $34\left(\mathrm{MnCl}_{2}\right)$, sulphur powder duly wrapped in 87

made to four sets of castings respectively while one set was not modified to serve as the control.

\subsection{Mechanical Testing and Metallography}

Tensile properties of the alloys were determined from ASTM standard tensile test bars machined from the cast cylindrical bars, in as cast condition using a Universal Testing Machine. Hardness test was carried out on 15 $\mathrm{mm}$ diameter x $10 \mathrm{~mm}$ long cylindrical test bars machined from the cast cylindrical bars in the as-cast condition using a Rockwell hardness tester. Microstructural analysis was carried out on the specimens prepared from the broken tensile test bars to examine the effect of the modifier additions on the morphology of the eutectic silicon phase. This was performed using an OLYMPUS optical microscope. The surfaces of the specimens were ground with different grades of emery paper from rough to fine grades. The final polishing was done on a Struers-Rotopol-V polishing machine using diamond paste and polishing cloth. The samples were etched with caustic soda solution (1g sodium hydroxide; $99 \mathrm{~cm}^{3}$ water) [17].

\section{Results and Discussion 3.1 Microstructural Studies}

Figures $1 \mathrm{a}$ and $1 \mathrm{~b}$ are micrographs of unmodified $\mathrm{Al}-12 \mathrm{wt} \% \mathrm{Si}$ alloy casting in as cast condition showing microstructures in which the eutectic silicon phase is dispersed in the aluminum matrix with needle-like morphology which is actually plate or flake-like in three dimension. Addition of $0.02 \%$ sulphur to the alloy produces fine eutectic silicon morphology (Figure 2). There seems to be the presence of few coarse silicon particles sparsely dispersed in the aluminum matrix, otherwise the needle-like eutectic silicon has been transformed to fine scale structure.

Figure 3 shows that modifying the alloy with $0.05 \%$ sulphur gives a microstructure of fine fibrous eutectic silicon morphology devoid of any needle-like silicon structure. The microstructure is comprised of fine fibrous eutectic silicon of fairly uniform size and distribution in the aluminum matrix which is consistent with the effect of modification as reported by other researchers [5, 6, 18-20]. 


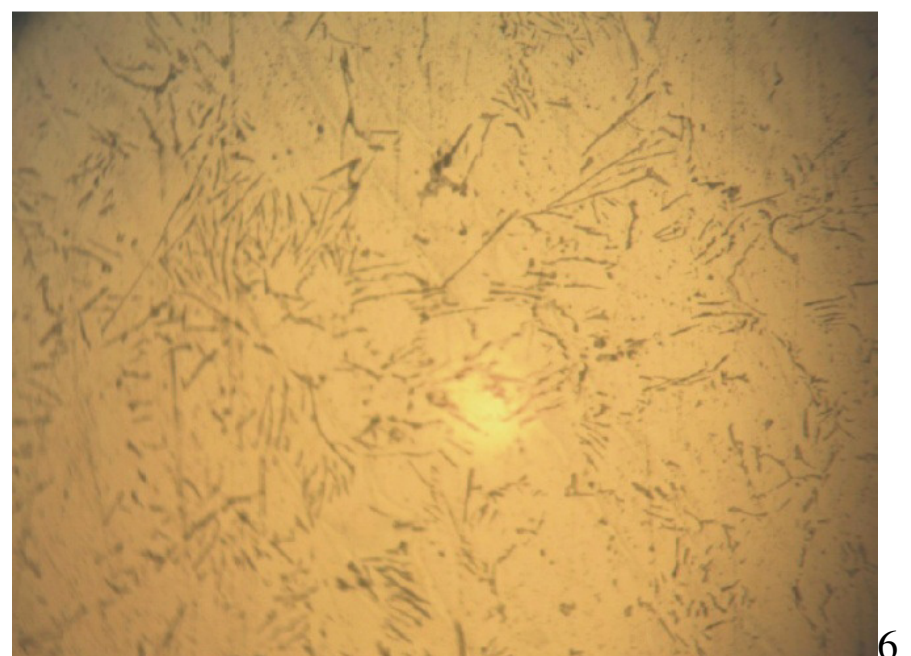

Figure 1a: Micrograph of unmodified Al-12wt\% Sil 7 alloy casting (200x).

5

6

7

8

9

10

11

12

13

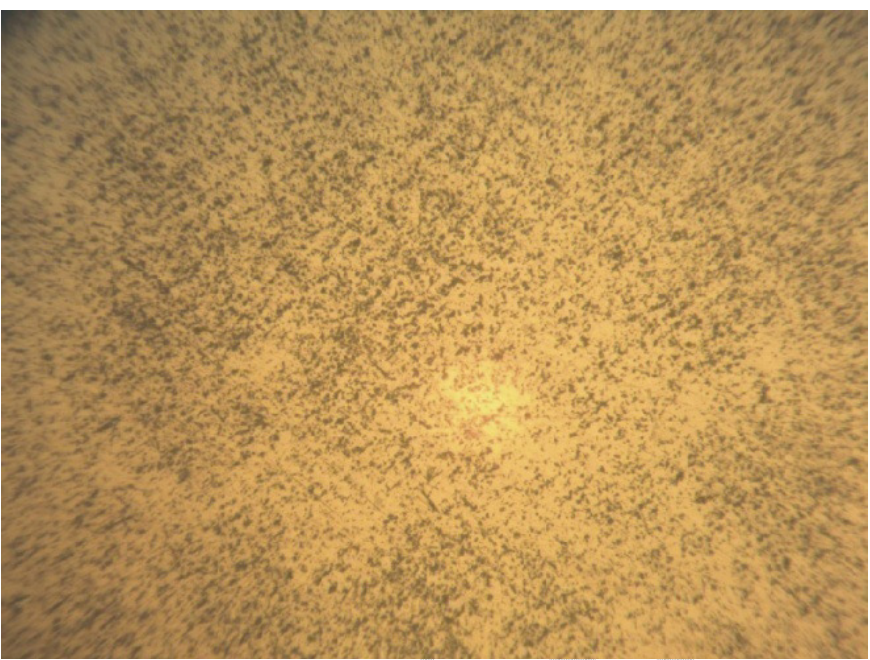

Figure 3: Micrograph of Al-12wt\%Si+ $0.05 \%$ Salloy casting (200x).

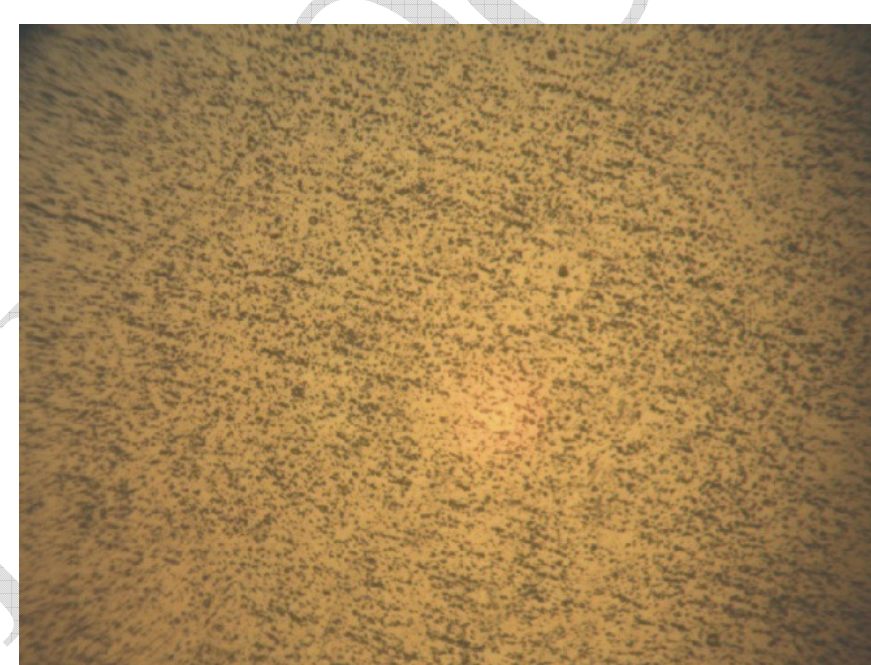

Figure 4: Micrograph of Al-12wt\%Si $+0.08 \% \mathrm{~S}$ alloy casting (200x).
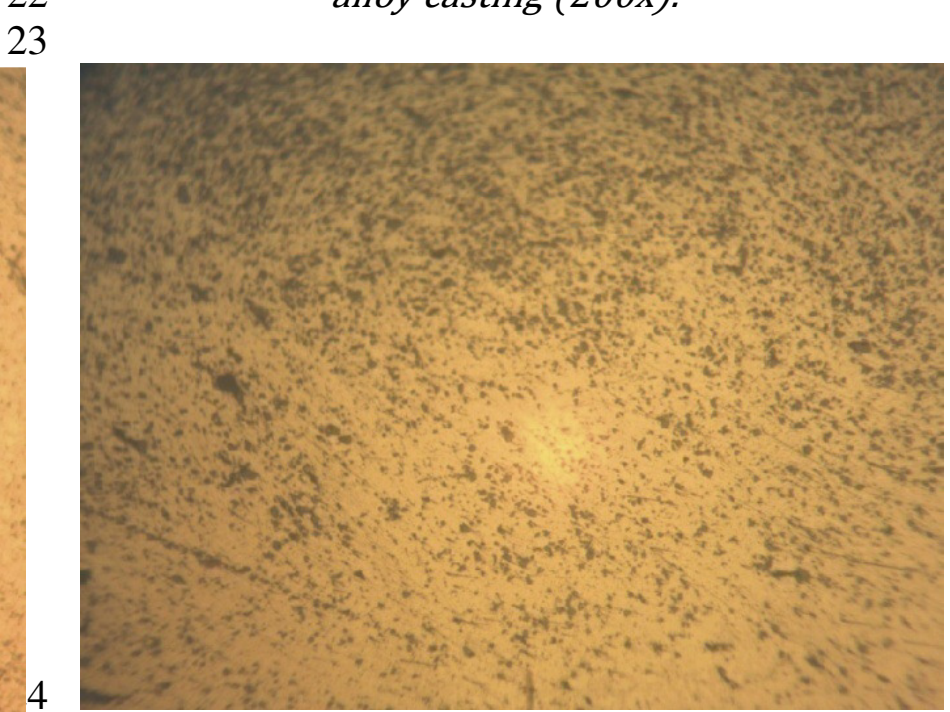

Figure 5: Micrograph of Al-12wt\%Si + 0.1\% Si alloy casting (200x).

$$
\text { alloy casting (200x). }
$$


1 Modifying the alloy with $0.08 \%$ sulphur produces 54

2 a microstructure of refined eutectic silicon55

3 structure though the silicon phase is not as fine as56

4 the one obtained for the $0.05 \%$ sulphur-modified57

5 alloy (Figure 4). The micrograph of the alloy58

6 modified with $0.1 \%$ sulphur shows the presence59

7 of fine eutectic silicon and coarse particles that60

8 may be silicon particles or other unidentified Al-61

9 Si phases unevenly dispersed in the aluminum62

10 matrix (Figure 5). This implies that the optima163

11 modification level of the alloy with sulphur has64

12 been exceeded.

13

14

3.2 Effect of Sulphur Addition on the 67 Mechanical Properties of Al-12wt\%Si Alloy68

The results of the mechanical properties of the 69 experimental alloy castings in as cast condition70 are presented in Figures 6-8. Figures 6-8 show the variation of mechanical72 properties of the various alloy castings with sulphur addition.

The unmodified alloy casting has UTS of 154.4 MPa and addition of $0.02 \%$ sulphur of the weight of the alloy significantly increases the UTS to approximately $178 \mathrm{MPa}$, followed by the alloy modified with $0.05 \%$ sulphur with UTS of 169.4 MPa. The alloys modified with $0.08 \%$ and $0.1 \%$ sulphur of the weight of the alloy have UTS of 161 and $160 \mathrm{MPa}$ respectively, which are not much higher than that of the unmodified alloy. The modified alloys show an increase in UTS as the modifier level is increased up to a certain point and then the UTS starts decreasing with $_{73}$ increasing modifier level, signifying that the 74 optimum addition level of the modifier has been75 exceeded. It can be seen from the result that there is also an initial increase in the $0.2 \%$ proof stress with increasing level of modifier addition followed by a decrease in the proof stress with increasing modifier level. The $0.02 \%$ sulphurmodified alloy gives the highest $0.2 \%$ proof stress of $126 \mathrm{MPa}$. The highest elongation of $9.2 \%$ is obtained for the alloy modified with $0.02 \%$ sulphur and on increasing the modifier level the elongation reduces until it gets to $4.6 \%$ for the alloy modified with $0.1 \%$ sulphur. The same trend is noticed in the hardness of the experimental alloys, with the alloy modified with $0.02 \%$ sulphur having the highest hardness value of HRA 47 while the one modified with $0.1 \% 76$ sulphur has the least hardness value of HRA 39.77 It can be seen from this experimental study that ${ }^{78}$ modification of Al-12wt\%Si sand cast alloy with sulphur improves the mechanical properties of the alloy in terms of the ultimate tensile strength, $0.2 \%$ proof stress, percentage elongation and hardness which is as a result of the modified eutectic silicon morphology obtained in the microstructure of the alloys. It can also be observed that very slight coarsening of the fine eutectic silicon structure occurs as the concentration of the sulphur increases beyond a certain level with attendant significant decrease in otherwise well improved mechanical properties though the mechanical properties still remain better than those of the unmodified alloy. The cause of this significant decrease in mechanical properties despite the still refined eutectic morphology may be the formation of a brittle sulphur compound in the alloy which, owing to its brittle nature, reduces the mechanical properties of the alloy.

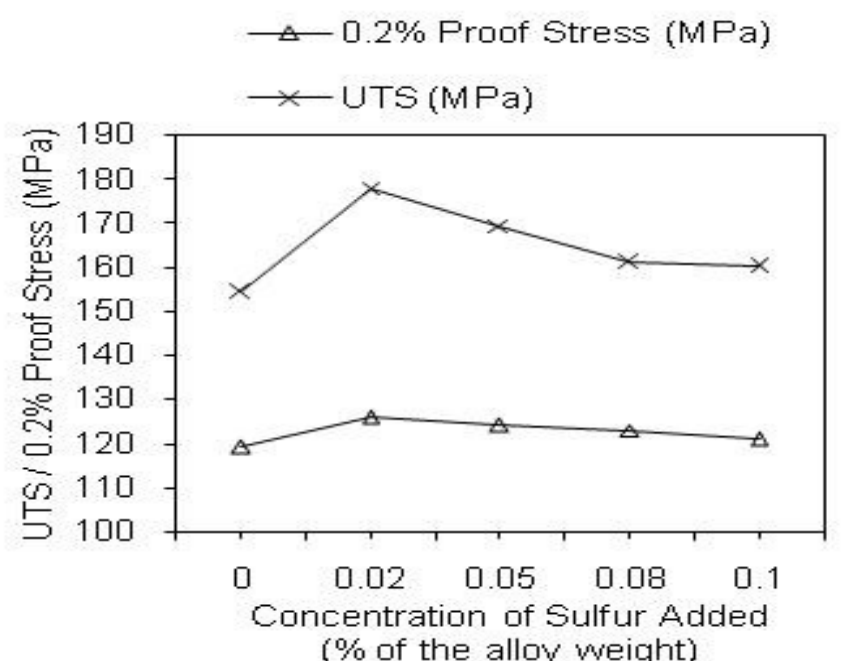

Figure 6: Variation of UTS $/ 0.2 \%$ Proof Stress of AI$12 w t \%$ Si sand cast alloy with sulphur addition.

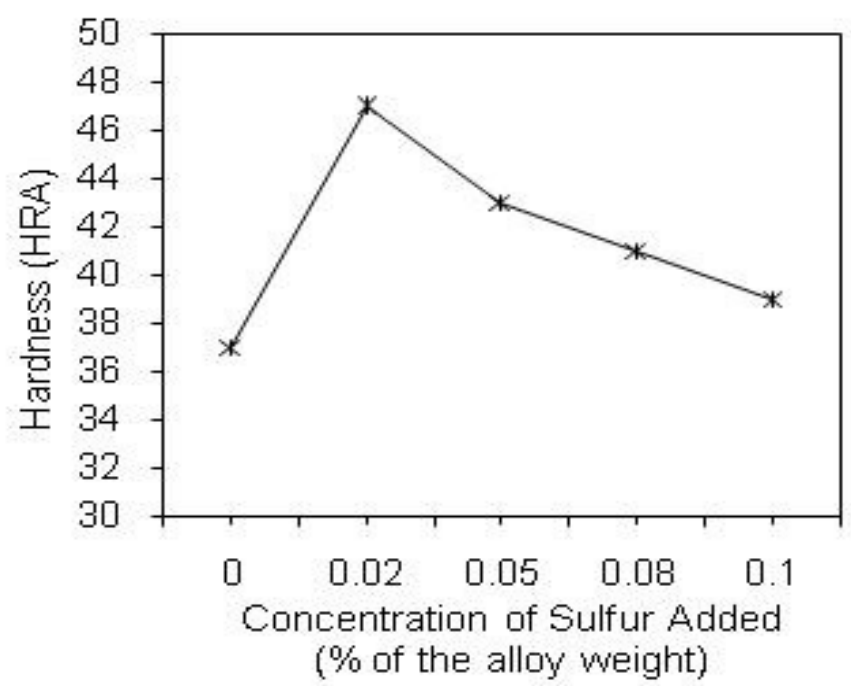

Figure 7: Variation of Hardness of Al-12wt\%Si sand cast alloy with sulphur addition. 


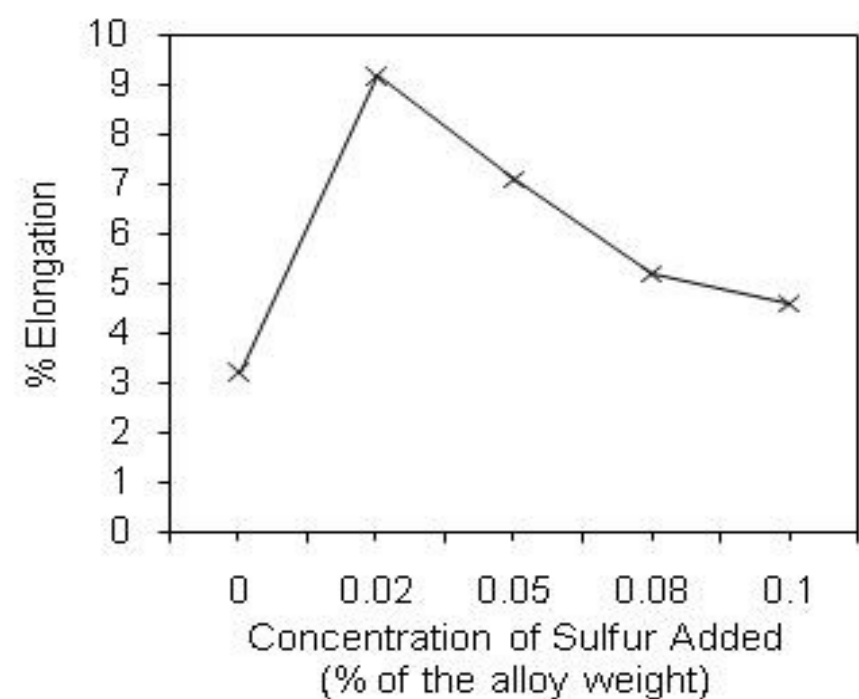

Figure 8: Variation of \% Elongation of Al-12wt\%Si sand cast alloy with sulphur addition. $\quad 56$

4

5 This possible explanation could be said to be $\mathrm{b}^{58}$

6 similar by analogy to that found in steel where59

7 the presence of brittle sulphides at the grain 60

8 boundary interfaces decreases the mechanical 61 9 properties of the steel [21]. Further studies to ${ }^{62}$

\section{References}

[1] Singh, V. Physical Metallurgy, Standard Publishers Distributors, Delhi, India, 1999.

[2] Shankar S., Riddle Y. W. and Makhlouf M. M. "Nucleation Mechanism of the Eutectic Phases in Aluminum-Silicon Hypoeutectic Alloys", Acta Materialia, Vol. 52, Number 15, 2004, pp 44474460.

[3] Yilmaz F. and Elliott R. J. "The Microstructure and Mechanical Properties of Unidirectionally Solidified Al-Si Alloys", Journal of Materials Science, Vol. 24, Number 6, 1989, pp. 20652070.

[4] Pena B. S. and Lozano J. A. "Microstructure and Mechanical Property Developments in Al-12Si Gravity Die Castings after Ti and/or Sr Additions", Materials Characterization, Vol. 57, Number 4-5, 2006, pp. 218-226.

[5] Hanna M. D., Lu S. Z. and Hellawell A. "Modification in the Aluminum Silicon System", Metallurgical and Materials Transactions A, Vol. 15, Number 3, 1984, pp. 459-469.

[6] Kim C. B. and Heine P. W. "Fundamentals of Modification in the Aluminum-Silicon System", Journal of the Institute of Metals, Vol. 92, 1963, pp. 367-376

[7] Pacz A., US Pat. 1387900, 1921

[8] Qiyang L., Qingchun L. and Qifu L. "Modification of Aluminum-Silicon Alloys with Sodium", ActaMetallurgica et Materialia, Vol. 39, Number 11, 1991, pp. 2497-2502.

[9] Dahle A. K. and Hillert M., "Reply to Discussion on Nucleation Mechanism of Eutectic Phases in Aluminum-Silicon Hypoeutectic Alloys", Metallurgical and Materials Transactions A, Vol. 37, Number 4, 2006, p. 1353.

[10] Shankar S., Riddle Y. W. and Makhlouf M. M. "Eutectic Solidification of Aluminum-Silicon Alloys", Metallurgical and Materials Transactions A, Vol. 35, Number 9, 2004, pp. 3038-3043.

[11] Robles Hernandez F.C. and Sokolowski J. H. "Novel Image Analysis to Determine the $\mathrm{Si}$ Modification for Hypoeutectic and Hypereutectic Al-Si Alloys", JOM, Vol. 57, Number 11, 2005, pp. 48-53.

[12] McDonald S.D., Nogita K., Dahle A.K., Taylor J.A. and St.John D.H. "Eutectic Solidification and Porosity Formation in Al-Si Alloys: Role of Strontium", Transactions of the American Foundry Society (AFS Trans.), Vol. 108, Paper Number 00-115, 2000, pp. 463-470. 
[13] Shivkumar S., Wang L. and Apelian D. "Molten22 Metal Processing of Advanced Cast Aluminium23 Alloys", Journal of Metals (JOM), Vol. 4324 Number 1, 1991, pp. 26-32.

[14] Fang Q.T. and Granger D.A. "Porosity Formation26 in Modified and Unmodified A356 Alloy27 Castings", Transactions of the Americam Foundry Society (AFS Trans.), Vol. 97, 1989, $\mathrm{pp}_{29}^{28}$ 989-1000.

[15] Miresmaeili S.M., Campbell J., Shabestari S.G31 and Boutorabi S.M.A. "Precipitation of Sr-rich32 Intermetallic Particles and their Influence on $_{33}$ Pore Formation in Sr-modified A356 Alloy" 33 Metallurgical and Materials Transactions A, Vol 34 36, Number 9, 2005, pp. 2341-2349.

[16] Gruzleski J.E. and Closset B.M. "The Treatment37 of Liquid Aluminum-Silicon Alloys", American 38 Foundry-men's Society Inc., Des Plaines, Illinois 39 USA, 1990, pp. 57-157. 40

[17] Higgins R. A. Engineering Metallurgy, Part 1, Applied Physical Metallurgy, English Language
Book Society and Hodder and Stoughton, London, 1973.

[18] Makhlouf M. M. and Guthy H. V. "The AluminumSilicon Eutectic Reaction: Mechanisms and Crystallography," Journal of Light Metals, Vol. 1, Number 4, 2001, pp. 199-218.

[19] Chai G. and Backerud L. "Factors Affecting Modification of Al-Si Alloys By Adding SrContaining Master Alloys", Transactions of the American Foundry Society (AFS Trans.), Vol. 100, 1992, pp. 847-857.

[20] Martínez E., Cisneros D. M., Valtierra G. S. and Lacaze J. "Effect of Strontium and Cooling Rate upon Eutectic Temperatures of A319 Aluminum Alloy," ScriptaMaterialia, Vol. 52, Number 6, 2005, pp. 439-443.

[21] Linchevsky B., Sobolevsky A. and Kalmenev A. Iron \& Steel Making, MIR Publishers, Moscow, 1983. 